University of Wollongong

Research Online

Faculty of Engineering and Information

Faculty of Engineering and Information

Sciences - Papers: Part A

Sciences

$1-1-2010$

Using a social informatics framework to study the effects of location-based social networking on relationships between people: A review of literature

Sarah Jean Fusco

University of Wollongong, sjf462@uow.edu.au

Katina Michael

University of Wollongong, katina@uow.edu.au

M G. Michael

University of Wollongong, mgm@uow.edu.au

Follow this and additional works at: https://ro.uow.edu.au/eispapers

Research Online is the open access institutional repository for the University of Wollongong. For further information contact the UOW Library: research-pubs@uow.edu.au 


\title{
Using a social informatics framework to study the effects of location-based social networking on relationships between people: A review of literature
}

\author{
Abstract \\ Location based social networking (LBSN) applications are part of a new suite of emerging social \\ networking tools that run on the Web 2.0 platform. LBSN is the convergence between location based \\ services (LBS) and online social networking (OSN). LBSN applications offer users the ability to look up the \\ location of another "friend" remotely using a smart phone, desktop or other device, anytime and \\ anywhere. Users invite their friends to participate in LBSN and there is a process of consent that follows. \\ Friends have the ability to alter their privacy settings to allow their location to be monitored by another at \\ differing levels of accuracy (e.g. suburb, pinpoint at the street address level, or manual location entry). \\ This paper explores the impact of LBSN upon society, especially upon trust between friends. The study \\ used focus groups to collect data, and a qualitative approach towards analysis. The paper concludes that \\ while there are a great many positive uses of LBSN, there are some significant problems with current \\ applications, and that better design is required to ensure that these technologies are not exploited against \\ a user to commit harm.

\section{Keywords} \\ networking, review, location, literature, effects, study, social, people, framework, between, informatics, \\ relationships

\section{Publication Details} \\ Fusco, S. Jean., Michael, K. \& Michael, M. G. (2010). Using a social informatics framework to study the \\ effects of location-based social networking on relationships between people: A review of literature. \\ International Conference on Mobile Business (pp. 157-171). Greece: IEEE.
}




\title{
Using a Social Informatics Framework to Study the Effects of Location-Based Social Networking on Relationships between People: A Review of Literature
}

\author{
Sarah Jean Fusco, Katina Michael, M.G. Michael \\ School of Information Systems and Technology, Faculty of Informatics, University of Wollongong \\ \{sjf462,katina,mgm\}@uow.edu.au
}

\begin{abstract}
This paper is predominantly a review of literature on the emerging mobile application area known as location-based social networking. The study applies the social informatics framework to the exploratory question of what effect location based social networking may have on relationships between people. The classification model used in the paper relates previous research on location based services and online social networking together. Specifically the wider study is concerned with literature which identifies the impact of technology on trust with respect to friendship. This paper attempts to draw out the motivations behind using location based social networking applications and the implications this may have on individual privacy and more broadly one's social life. It relies heavily on the domain of social informatics with a view to setting a theoretical underpinning to the shaping between context and information and communication technology design.
\end{abstract}

\section{Introduction}

The purpose of this paper is to provide a review of the relevant literature of the effects of location-based social networking (LBSN) on relationships between people. There are three main areas of literature reviewed. The first area is literature related to the domain of social informatics. The purpose of reviewing this literature is to guide the conduct of the wider research study. The second area of literature reviewed is the social informatics based studies on online social networking (OSN), location based services (LBS), and location based social networking (LBSN). The purpose of reviewing the literature on online social networking and location based services is because these technologies precede location based social networking. LBSN is the composite of LBS and OSN and therefore the literature on each of these technologies provides insight into core concepts related to location based social networking. The intersection between LBS, ONS and LBSN also uncovers an area which has been under researched predominantly due to its newness in the field of information and communication technology (ICT). The third area of literature reviewed by this research is the literature on trust and friendship. The purpose of briefly reviewing this literature is to provide an outline of the social theory that forms the background of the wider study. Prior to reviewing the literature a classification model is presented which summarizes the literature in the domain, in addition to providing a roadmap for this paper.

\section{Background}

Location Based Social Networking (LBSN) applications such as Google Latitude, Loopt and BrightKite enhance our ability to perform social surveillance. These applications enable users to view and share real time location information with their "friends". LBSN applications offer users the ability to look up the location of another "friend" remotely using a smart phone, desktop or other device, anytime and anywhere. Users invite their friends to participate in LBSN and there is a process of consent that follows. Friends have the ability to alter their privacy settings to allow their location to be monitored by another at differing levels of accuracy (e.g. suburb, pinpoint at the street address level, or manual location entry). Individuals can invite friends they have met in the physical space, friends they have met virtually in an online social network, their parents, their siblings, their extended family, partners, even strangers to join them in an LBSN setting.

With the emergence of this technology it is crucial to consider that "technology alone, even good technology alone is not sufficient to create social or economic value" [1]. Further to not contributing "sufficient" economic or social value, Kling and other scholars have identified that technologies can have negative impacts on society [2]. Consider the case of persons who have befriended each other in the virtual space, only to meet in the physical space and to encounter unforeseen consequences by doing so [3]. As location based social networking technologies are used between what is loosely termed "friends," they have the potential to impact friendships, which are integral not only to the 
operation of society but also to the individual's well being [4].

\section{Classification Model}

The classification model of the literature review expressed in Figure 1 summarizes the current social informatics based scholarship on location based services, online social networking and location based social networking applications. The arrows indicate the researchers view that location based social networking applications are novel in that they have been designed to provide additional functionality for social networking. The classification model also summarizes the scholarship on trust and technology and introduces the social theory of trust and friendship. The purpose of reviewing this literature is first to identify studies relating trust to LBS and OSN, and then to understand how technology has the potential to impact upon human trust. Although it must be stated upfront that the number of studies relating to this particular research question are scarce, given that the first popular LBSN application was launched in the beginning of 2009 [5], with only beta applications existing in August of 2008. Secondly, the purpose of reviewing the literature on trust and friendship is to develop a social theory to inform the research.

In order to logically understand the literature it is organized in a top-down approach. First the paper addresses enquiries in the domain of social informatics. Second the literature on online social networking and location based services is reviewed, providing a background to the types of issues pertinent to location based social networking. The review of the literature specifically on LBSN then follows. Once the gap in current research is presented, previous works on 'trust and technology', and 'trust and friendship' are presented.

[Parent Theory/Framework]

SOCIAL INFORMATICS

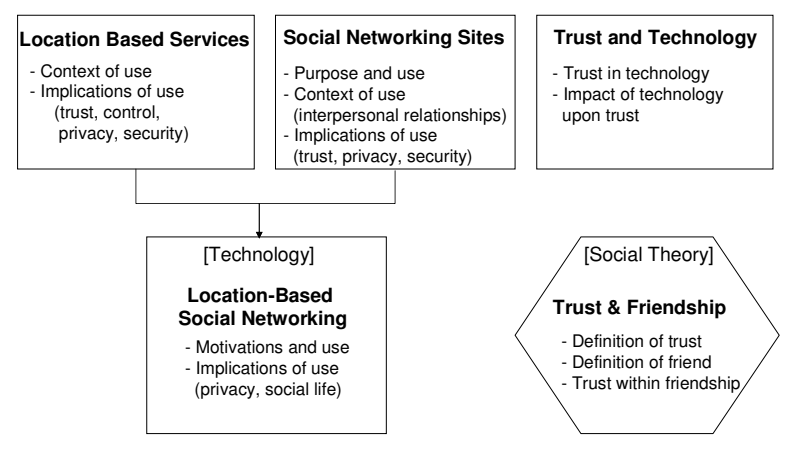

Figure 1. Classification Model

\section{Socio-Technical Network Influences}

The social implications of technologies have been explored under several different theoretical frameworks, including technological determinism, social shaping of technology, critical information theory and social informatics. This research adopts the approach of social informatics. Thus the overall aim of the research is to engage in a holistic and empirical study of the 'consequences' of location based social networking applications. This section provides a definition and outline of social informatics, how and why it has developed and how it can be used as a framework for further research. This section concludes with a justification for the adoption of this particular approach against a backdrop of other possible theories.

\subsection{Definition of Social Informatics}

Social informatics research focuses upon the relationships between information and communication technologies (ICTs) and the larger social context they exist within [6]. The definition of social informatics provided by the Encyclopedia of Library and Information Science defines Social Informatics as [7]:

"the systematic, interdisciplinary study of the design, uses and consequences of information technologies that takes into account their interaction with institutional and cultural contexts. Thus, it is the study of the social aspects of computers, telecommunications, and related technologies, and examines issues such as the ways that IT shape organizational and social relations, or the ways in which social forces influence the use and design of IT... Social Informatics research strategies are usually based on empirical data... [and] use data to analyze the present and recent past to better understand which social changes are possible, which are plausible and which are most likely in the future."

One of the key concepts underlying the approach of social informatics is that information and communication technology are not designed in social isolation, that a social context does exist, and it does influence the manner in which ICT is developed, used and ultimately has a social impact [7].

\subsection{The Development of Social Informatics}

Social informatics research was born from the dissatisfaction with previous information systems research methods that were focused on either exploring the deterministic effects of technology upon society, or society upon technology. These theories are respectively 
referred to as technological determinism and social shaping of technology.

Technological deterministic research studies focus on the impact of technology upon society. The research approach aims to answer questions such as:

"What would be the impact of computers on organizational behavior if we did X? What would be the changes in social life if we did X? Will computer systems improve or degrade the quality of work?...'What will happen, X or Y?' The answer was, sometimes $\mathrm{X}$, and sometimes $\mathrm{Y}$.

There was no simple, direct effect" [8].

Technological determinism has failed to produce satisfactory prediction and this has lead to the formation of social informatics research [9]. Technological determinism was also seen by the proponents of the social shaping of technology, as being only a partial truth, and "oversimplistic" [10].

The social shaping of technology approach proposes that technology is not an autonomous entity as it is shaped by social forces. This is in direct opposition to technological determinism which depicts technology as an "autonomous entity, which develops according to an internal logic and in a direction of its own, and then has determinate impacts on society" [11]. Social shaping of technology studies aim to show that technology is in fact a social product, it does not mold society, but rather society molds it, and this can be seen by investigating the social forces at play in the creation and use of technology [12]. Examples of approaches in the social shaping of technology include the social construction of technology and the actor network theory. These theories focused on the role of either knowledge or actors upon the development of technology. Technological determinism focuses on the impacts of technology, while the social shaping of technology focuses on the context. Social informatics on the other hand "investigates how the influences and nodes in a sociotechnical network shape each other" [13].

Social informatics does not ask deterministic questions 'What will happen $\mathrm{X}$ or Y?', instead social informatics researchers asks the question 'When will $\mathrm{X}$ happen? And Under what Conditions?' providing a nuanced conceptual understanding of the operation of technology in social life [9]. In contrast to technologic determinism and social shaping of technology theories, the social informatics framework highlights the mutual shaping of technology and society, both molding each other at the same time.

\subsection{Examples of Social Informatics Research}

Social informatics takes a nuanced approach to investigating technologies and explores the bidirectional shaping between context and ICT design, implementation and use [13] (figure 2). This approach, which combines the social aspects and the technical aspects of technology, has been found to be useful for understanding the social shaping and 'consequences' of information communication technologies [9]. Examples of social informatics research include the vitality of electronic journals [14], the adoption and use of Lotus Notes within organizations [15], public access to information via the internet [16], and many other studies. Social informatics research also investigates new social phenomenon that materialize when people use technology, for example, the unintended effects of behavioral control in virtual teams [17]. Research falling in this area is perceived as the future direction for social informatics research [9].

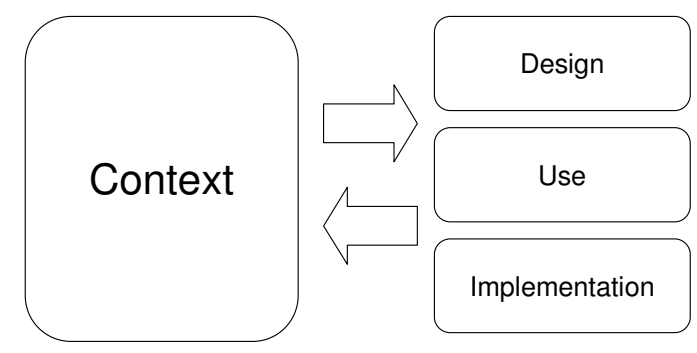

Figure 2. Bidirectional Shaping between Context and ICT Design

\subsection{Social Informatics as a Framework}

Social informatics is not described as a theory, but as a "large and growing federation of scholars focused on common problems", with no single theory or theoretical notion being pursued [13]. What social informatics does provide is a framework for conducting research. What follows is a description of the framework, its key elements and distinguishing features.

4.4.1. Key Features of Social Informatics Research. Social informatics research is problem orientated, empirical, theory based and interdisciplinary with a focus on informatics (table 1). In addition there are several key distinguishing features of the framework. First, social informatics does not prescribe a specific methodology although the majority of methods employed by researchers in this field are qualitative methods. Second, social informatics is inclusive of normative, analytical or critical approaches to research. Third, this type of research "investigate[s] how influences and nodes at different levels in the network shape each other" [13], engaging in analysis of the interconnected levels of the social context. Fourth, research in this field can be seen to fall within three broad themes: 
(1) ICT uses lead to multiple and sometimes paradoxical effects,

(2) ICT uses shape thought and action in ways that benefit some groups more than others and these differential effects often have moral and ethical consequences and;

(3) a reciprocal relationship exists between ICT design, implementation, use and the context in which these occur [13].

When adopting the framework of social informatics, the main focus of social informatics should not be overshadowed. The research should be focused upon the idea that "ICT are inherently socio-technical, situated and social shaped" [18] and that in order to understand their impacts we need to explore, explain and theorize about their socio-technical contexts [13].

Table 1. Key Features of Social Informatics Research (adapted from [13])

\begin{tabular}{|l|l|}
\hline Features & Description \\
\hline Problem- & $\begin{array}{l}\text { Research in this field seeks to expose the problems } \\
\text { which arise from the "bidirectional relationship } \\
\text { between social context and ICT design, } \\
\text { implementation and use" By exploring the } \\
\text { bidirectional relationship between technology and } \\
\text { its context the researcher is able to identify the } \\
\text { problems that are created by the introduction of } \\
\text { the technology. }\end{array}$ \\
\hline Empirical & $\begin{array}{l}\text { The research gathers empirical evidence to } \\
\text { understand the socio-technical context, which the } \\
\text { technology operates within, in order to "help make } \\
\text { sense of the vexing issue people face when they } \\
\text { work and live with computing". }\end{array}$ \\
\hline Theory-Based & $\begin{array}{l}\text { Social informatics research utilizes social theories } \\
\text { in order to understand and explore the context in a } \\
\text { holistic manner. A "social theory" is one which } \\
\text { "seeks to represent, define and predict how } \\
\text { humans enact and maintain social order, social } \\
\text { structures and social interactions". }\end{array}$ \\
\hline $\begin{array}{l}\text { Interdisciplinary } \\
\text { but focused on } \\
\text { Informatics }\end{array}$ & $\begin{array}{l}\text { Social Informatics is also a means of linking other } \\
\text { disciplines with Informatics. Informatics itself } \\
\text { refers to the "study of information content, } \\
\text { representation, technology, and the methods and } \\
\text { strategies associated with its use". }\end{array}$ \\
\hline
\end{tabular}

\subsection{Justification for Using the Social Informatics Framework}

There are two primary justifications for adopting a social informatics approach. First, the goals and achievements of social informatics accords to the researchers' goal and motivation. Second, the holistic method of enquiry adopted by social informatics research provides meaningful data. Social Informatics researchers aim to develop: "reliable knowledge about information technology and social change based on systematic empirical research, in order to inform both public policy issues and professional practice" [8]. This is in accordance with the researchers' goal to identify the credible threats that LBSN pose to friends and society with a view to preventing or minimizing their effect. Social informatics research has also developed an "increased understanding of the design, use, configuration and/or consequences of ICTs so that they are actually workable for people and can fulfill their intended functions" [9]. In essence, this is the primary motivation behind this study: to increase our understanding of location based social networking so that it can be workable and fulfill its intended function in society without causing individuals harm.

The method of enquiry adopted by social informatics researchers is usually based on conducting a holistic and interdisciplinary investigation into the bidirectional relationship between context and ICT design, use and implementation. This study takes into account the social theory surrounding trust and relationships; thus providing meaningful data on the implications of location based social networking upon trust. For Kling, it was the fact that information and communication technologies were increasingly becoming enmeshed in the lives of more and more people, that there was a pressing need to explore the ultimate social consequences of the ensuing changes [8]. Kling considered that studying new and emerging applications early in the process of diffusion granted significant opportunities to shape the forms and uses of new technologies.

\subsection{Alternative Theories and Approaches to the Study of the Social Implications of Technology}

Two alternative approaches to social informatics were discussed in section 4.2, i.e., technological determinism and the social shaping of technology. A third possible theory that was considered was critical social theory (founded by Jürgen Habermas). Critical social theory has four distinct attributes: (1) it is sensitive to lifeworlds of the organizational actors and is oriented to interpreting and mapping the meanings of their actions from their perspectives, (2) adopts pluralistic methods, (3) does not separate the subjects of inquiry from their context and (4) recognizes that the context is not only important to meaning construction, but to social activity as well [19]. Thus, we can say, that critical social theory is similar to social informatics in three main ways: (1) both approaches are sensitive to the context surrounding the subject of enquiry, (2) both focus on the inter-relationship between context and subject, and (3) both approaches employ pluralistic methods. However, the main focus of the two approaches is markedly different.

Critical information theory focuses on "questioning the conventional wisdom of prevailing schools of thought and institutional practices with a primary focus on issues related to justice and power" [20]. In applying 
this kind of approach to ICT we would be aiming to "discover and expose attempts to design and (mis)use IS to deceive, manipulate, exploit, dominate and disempower people" [21]. This is not the aim of the research problem presented here- while admittedly location based social networking can cause harm if misused (e.g. stalking by x-partners), it can also act to be incredibly beneficial (e.g. in a family travel holiday in a foreign country). Thus, the aim of the research is to understand the positive and negative implications of the use of location based social networking in society, not just to look at issues of justice and power.

The following section provides an overview of the key literature on the use, design, implementation, context and implications of online social networking, location based services, and location based social networking.

\section{Online Social Networking Sites}

Current studies on online social networking sites use varied methods involving case studies, surveys, interviews and observations to investigate the use, implications, design and context of the emerging application. The literature on OSN falls into three broad areas of study: (1) purpose, motivation and patterns of use, (2) effect on interpersonal relationships, and (3) threats to privacy, trust and security.

\subsection{Purpose, Motivation and Patterns of Use}

These studies on online social networking outline the purpose for which OSN is used, the motivation behind an individual's use of OSN, and how users go about the adoption of OSN applications.

5.1.1. Purpose of Online Social Networking. The purpose of OSN has been identified as the public articulation of individual social connections [22], the creation of an information ground [23] or a means of satisfying "our human tendencies towards togetherness" [24]. Boyd's study on Friendster users, revealed that OSN "reshaped how groups of people verbally identify relationships and solidified the importance of creative play in social interactions" [22]. Boyd identified the value of networks, how users presented themselves on Friendster, who users connected with from exiting friends to "hook-ups" to "familiar strangers," and it highlighted the dilemma caused by fakesters in the network.

Counts and Fisher's study explored OSN exposing the "types and usefulness of information shared in everyday life, the way the system fits into participants communication and social "ecosystem" and the ways in which the system functions as an information ground" [23]. Other than just a source of information, OSN also functions to provide "a logical extension of our human tendencies towards togetherness" [24]. Weaver and Morrison perform case studies on four social networking sites (mySpace, Facebook, Wikipedia and YouTube) to explore the range of socialization that can occur revealing the core purpose of connecting to people.

\subsubsection{Motivation Behind the Use of Online Social} Networking. Lampe, Ellison and Steinfield have conducted two major survey studies on the use of OSN. The first study was in 2006, and the second was in 2008. The purpose of the first study was to answer the question - "Are Facebook members using the site to make new online connections, or to support already existing offline connections?" The results revealed that Facebook users are primarily interested in increasing "their awareness of those in their offline community" [25]. The second study incorporated three surveys and interviews in order to explore whether the use, perception of audience and attitudes of users of Facebook changed over time with the introduction of new features to Facebook. The results again revealed that the primary use of Facebook was to maintain existing offline connections, in order to: keep in touch with friends, learn more about existing classmates and people that users have met socially offline [26]. Both studies were conducted upon undergraduate university populations.

Joinson [27] performed a use and motivation study on a random sample of Facebook users, not limited to campus-based populations, which supported the conclusions of both Lampe, Ellison and Steinfield studies. Furthermore the study by Joinson probed further identifying seven unique uses and gratifications of online social networks, including social connection, shared identities, content, social investigation, social network surfing and status updating, and identifying that different uses and gratifications relate differentially to patterns of usage [27].

5.1.3. Patterns of Use of Online Social Networking. Other studies of use of online social networking have looked at how the information provided by social networking sites can be used to understand patterns of use. Hancock, Toma and Fenner [28] explore how people use information available on social networking sites to initiate relationships. They asked participants to befriend partners via an instant messaging conversation by using profile information readily available on Facebook. This use of asymmetric information revealed that the information helped in linking persons together, but only in 2 out of 133 scenarios did the users realize that information had been gained from their Facebook profile, instead of the real-time instant messaging conversation(s) they had had with the friend. This study highlighted the rich source of information about the self 
which is available online, as well as the unintended consequences of others strategically plotting to use that information for their own relational goals.

Online social networking researchers have also explored patterns of use among different groups of people and communities. Ahn and Han [29] investigated the typological characteristics of online networking services. Chapman and Lahav [30] conducted an ethnographic interview studying the cross-cultural differences in usage patterns of OSN in multiple cultures. Results from the interviews identified three dimensions of cultural difference for typical social networking behaviors: users' goals, typical pattern of self expression and common interaction behaviors. The study was limited to the interviews with participants from the United States, France, China and South Korea, and therefore requires future work to evaluate the presented results.

Other studies have explored the usage among different age groups. Arjan, Pfeil and Zaphiris [31] explored users MySpace friend networks with webcrawlers to compare teenage (13-19) networks with those of older people $(60+)$. The findings of the study showed that teenage users had larger networks with more users of the same age than older users. Furthermore when representing themselves online teenagers use more self referencing, negative emotions and cognitive works than older people. The limitation of this study is the small sample size and limited frame of reference - that is the differences between teenagers and older people without reference to other intermediate age groups. A third study by Schrammel, Köffel and Tscheligi [32] surveyed users of various online communities to explore the different information disclosure behavior in the different types of online communities. They identified that users disclose more information in business and social contexts, with students being more freehanded with information than employed people, and females being more cautious than males. Studies relating to the use of OSN have also explored its potential application to other contexts including the workplace [33], [34]; student learning [35], citizen involvement [36] and connecting women in information technology [37].

\subsection{The Effect of Online Social Networking on Interpersonal Relationships}

Online social networking is used in the context of being social, creating connections with users and expanding networks [38]. The implication of using OSN to create or maintain relationships has been explored by several researchers highlighting the nature of intimate online relationships and social interactions as well as the benefits and detriments of the use of OSN upon relationships. Boyd's study concentrated on intimacy and trust within the OSN site Friendster. He highlighted that intimate computing hinges upon issues surrounding trust, trust in the technology, and ultimately trust in the other users to operate by the same set or rules [39]. Dwyer [40] has presented a preliminary framework modeling how attitudes towards privacy and impression management translate into social interactions within MySpace. Other issues that have been explored in the literature include whether interaction between users, flow from the declaration of friends and whether users interact evenly or lopsidedly with friends. These questions were explored by Chun et al, in a quantitative case study of the OSN site Cyworld, reporting that there was a high degree of reciprocity among users [41].

The benefits and detriments of OSN upon interpersonal relationships have not been extensively explored. A survey of undergraduate university students conducted by Ellison, Steinfield and Lampe [42] identified that using Facebook benefits the maintenance and growth of social capital among "friends" and also improves psychological well being. However, although OSN sites reinforce peer communication, Subrahmanyam and Greenfield [43] point out that this may be at the expense of communication within the family, expressing the need for further research into the affects of OSN upon real world communications and relationships.

\subsection{Implications of Use- Privacy, Trust and Security}

5.3.1. Privacy. Privacy in online social networking sites has received significant attention, with researchers exploring patterns of information revelation and implications upon privacy [44], the use of OSN policies to ensure privacy [45], differences in perceptions of privacy across different OSN [46], the privacy risks presented by OSN [47], mechanisms to enhance privacy on OSN [48], user strategies to manage privacy [49], and the notion of privacy and privacy risk in OSN [50].

The work of Levin and others at Ryerson University (the Ryerson Study) provides the largest survey on usage, attitudes and perceptions of risk of online social networking sites [50]. The design of the survey incorporated quantitative questions, scenarios and short answer questions to understand the level of risk and responsibility one feels when revealing information online. This study identified that young Canadians have a unique perception of network privacy "according to which personal information is considered private as long as it is limited to their social network" [50]. A further contribution of this study, along with other privacy studies [44], [46] is the implication of the use of online social networking sites upon trust. 
5.3.2. Trust. There are very few studies that explore the concept of trust in online social networking. The majority of studies which do look at trust are focused upon algorithms [51] or frameworks [52] that provide users of OSN with trust ratings. Other scant studies have mentioned or examined online social networking sites in terms of their impact upon trust in relationships. Gross and Acquisti [44] have mentioned that: "trust in and within online social networks may be assigned differently and have a different meaning than in their offline counterparts...[and that] trust may decrease within an online social network". However they did not investigate this aspect of OSN further. There are three studies which have investigated the impact of OSN upon trust. The first by Dwyer, Hiltz and Passerini [46], compares perceptions of trust and privacy between different OSN applications. The second study, conducted by Ryerson University, identifies the potential for OSN to impact upon trust, and the third study, by Gambi and Reader, is currently ongoing and aims to determine whether trust is important in online friendships and how it is developed.

Dwyer, Hiltz and Passerini [46] compared perceptions of trust and privacy concern between MySpace and Facebook. Trust was measured with the following two quantitative questions; "I feel that my personal information is protected by [social networking sites]" and "I believe most of the profiles I view on [social networking sites] are exaggerated to make the person look more appealing". The outcome of the study was focused upon trust in the users and online social network itself, but it did not shed light upon the effect of OSN upon trust in relationships.

The Ryerson study provides some exploration into the impact of online social networking sites upon trust in relationships, by presenting scenarios where users had experienced a loss of trust with other members of the site. The participants were then asked whether they had experienced or know of someone who had experienced such a scenario. The first scenario presented a user who went out partying and photographs were taken of the occasion and displayed on Facebook, resulting in the loss of trust by the family. Sixty-four percent of respondents either experienced this scenario directly or indirectly or heard of it happening to someone else. The second scenario that focused on trust involved a comment being posted upon a user's wall, indicating that that individual had been involved in shoplifting, and that no matter what the user claimed everyone still believed that he/she was a shoplifter. In this scenario, seventy-six percent of respondents reported that they had not heard of this occurring. The Ryerson study therefore presented a glimpse into the potential effect of use of online social networking sites upon trust. Another snapshot is provided by Gambi and Reader [53] who performed an online questionnaire with online social networking users to determine whether trust was important in online friendships, and how trust is developed online. Despite the low number of studies in the area of trust and OSN, it is clear from the currency of the three studies that this is an emerging area of research.

5.3.3. Security. Studies in online social networking have explored the impact of OSN on the security of user information and identity. A recent study by Bilge, Strufe, Balzarotti and Kirda [54] identifies the ease with which a potential attacker could perform identity theft attacks upon OSN and suggests improvements in OSN security.

\section{Location Based Services}

The focus of the literature on location based services, as with social networking, does not surround the technological aspects of design but the use and implications from a social informatics perspective. In this vein the literature reviewed identified the different contexts of use of LBS, the implications of use including trust, control, privacy and security.

\subsection{Context of Use of Location Based Services}

The literature identifies both current and future applications of LBS to track and monitor human subjects. These applications include employee monitoring [55], government surveillance [56], law enforcement [57], source of evidence [58], patient monitoring [59], locating family members for safety [60], [61], [62], locating students at school [63], identifying kidnapped victims [60], and socializing with friends [64], [65]. The following section details the literature conducted on humancentric LBS in terms of their social implications.

\subsection{Implications of Using Location Based Services}

Michael, Fusco and Michael's research note on the ethics of LBS provides a concise summary of the literature on the socio-ethical implications of LBS available prior to 2008 . The research note identifies trust, control, security and privacy [66] as the four implications of LBS. The literature pertaining to each of these implications will now be described.

6.2.1. Trust. The literature on trust and location based services has predominantly used scenarios [67], theory based discussion of workplace practices [68], and addressed consumer trust with respect to LBS [69]. To the researcher's knowledge, the investigation of trust and LBS is limited to these works. 
6.2.2. Control. Dobson and Fisher provide an account of the concept of "geoslavery", which is defined as "the practice in which one entity, the master, coercively or surreptitiously monitors and exerts control over the physical location of another individual, the slave" [70]. While Dobson and Fisher provide a theoretical account of the potential for "geoslavery" and the human rights issues which accompany it, Troshynski, Lee and Dourish examine the application of "geoslavery" upon paroled sex offenders who have been tracked using a LBS device [57].

Troshynski, Lee and Dourish's work draws upon two focus groups of parole sex offenders to explore the ways that LBS frame people's everyday experience of space. The findings from the focus groups draw out the notion of accountabilities of presence. Troshynski et al define accountabilities of presence as the notion that "[1]ocations are not merely disclosed, rather users are held accountable for their presence and absence at certain time and places" [57]. This presence need not be their actual physical location but the location that is disclosed to the observer. For instance, the parole sex offenders were "primarily concerned with understanding how their movement appear to their parole officers" [57]. This concept of being held to account is a mechanism of enforcing control.

A handful of studies have made mention of the parallel between LBS and Michel Foucault's Panopticon design for prisons [71], [57], [72]. The Panopticon prison was designed to be round so that the guards could observe the prisoners from the centre without the prisoners knowing whether they were being observed or not. Foucault argued "that the omni-present threat of surveillance renders the actual exercise of power (or violence) unnecessary; the mechanisms of pervasive surveillance induce discipline and docility in those who are surveilled" [57]. LBS represent a modern form of the Panopticon prison, exerting implicit control through the ability to observe.

6.2.3. Security. LBS can be used to provide security, such as law enforcement in order to make "police more efficient in the war against crime" [73] and also for border security [63]. However they can also present a threat to security [74].

6.2.4. Privacy. LBS pose a threat to privacy in the way that information is collected, stored, used and disclosed [75], [74], [76]. The threat to privacy is further exacerbated by the aggregation and centralization of personal information enabling location information to be combined with other personal information [77]. However while privacy is important, a hypothetical study requiring users to "imagine" the existence of a LBS, provided evidence to show that users were "not overly concerned about their privacy" [78]. Two other studies showed that in situations of emergency, individuals are more willing to forgo some of their privacy [60], [79].

\section{Location Based Social Networking}

The current literature on location based social networking explores users' willingness and motivations for disclosing location information and presents several user studies, which draw out different findings on the implications of using LBSN.

\subsection{Disclosure of Location Information}

Grandhi, Jones and Karam [80] conducted a survey to gauge attitudes towards disclosure of location information, and use of LBSN applications. The findings from the short survey indicated that there was a general interest in LBSN services. The majority of respondents stated that they would disclose their personal location data, that demographics and geotemporal routines did matter, and finally that social relationships are important in predicting when or with whom individuals want to share personal location data.

\subsection{LBSN User Studies}

7.2.1. LBSN Studies Based on Perceptions and Closed Environments. Several user studies have been conducted on location based social networking [81]. One of the earliest studies to be conducted involved a two phased study comparing perceived privacy concerns with actual privacy concerns within a closed LBS environment [82]. Barkhuus found that although users were concerned about their location privacy in general, when confronted with a closed environment the concern diminished. Another user study observed the configuration of privacy settings on a work-related location based service [83]. The study found that grouping permissions provided a convenient balance between privacy and control. Moving away solely from the concept of privacy, Consolvo and Smith [84] conducted a three phased study. First they explored whether social networking users would use locationenhanced computing, second they recorded the response of users to in-situ hypothetical requests for information, and thirdly requested participants to reflect upon phase one and two. Some of the captured results included: what participants were willing to disclose, the relationship between participant and requestor, the effect of where participants were located, the activity or mode, privacy classifications, what people want to know about another's location, and privacy and security concerns. The limitation of the research, and prior research on LBSN technologies was the hypothetical nature of the 
research, or that the research took place within a controlled environment. The following studies employed the use of actual or tailored LBSN.

7.2.2. Semi-Automated and Customizable LBSN Studies. Brown and Taylor [61] implemented the Whereabouts Clock, a location based service which displayed the location of family members on a clock face with four values. At any given point of time, an individual had the status of being at home, at work, at school, or elsewhere. This study revealed that LBSN within the family context could help co-ordination and communication and provide reassurance and connectedness, although it also caused some unnecessary anxiety. Privacy was found not to be an issue among family members using the Whereabouts Clock. The LBSN technology used in this study was more sophisticated than prior studies but it was rather limited in geographic granularity.

Humphreys performed a year long qualitative field study on the mobile social network known as Dodgeball which allowed users to 'check in' at a location and then that location was broadcasted to people on their given network. The outcomes of this study revealed patterns of use of LBSN, the creation of a "third space" by LBSN, and the resultant social molecularization caused by Dodgeball use [85]. The limitation of this study is again in the technology employed, the location information was not automated or real-time as Dodgeball required the user to consciously provide manual location updates.

Barkhuus and Brown [86] conducted a trial using Connecto, in order to investigate the emergent practices around LBSN. Connecto allowed users to tag physical locations and then the phone would automatically change the users displayed location to represent the tagged location. This provided a closer simulation of real-time automated LBSN. The outcomes of this study demonstrated that users could use Connecto to establish a repartee and were self-conscious about the location they disclosed. By publishing their location, the users were found to engage in ongoing story-telling with their friends, via a process of mutual monitoring. This act was seen as a "part of friendship relations" and added to an "ongoing relationship state." There was also the additional expectation that users had to "have seen each others' location or else risk falling 'out of touch' with the group" [86].

7.2.3. Real-time LBSN Studies. Brown LBSN studies published after the 2008 calendar year use methods that take advantage of sophisticated real-time automated LBSN applications. Tsai and Kelley [87] developed the Locyoution Facebook application which was used to automatically locate user laptops using wireless fidelity (Wi-Fi) access points leveraging the SkyHook technology. The aim of the study was to investigate how important feedback is for managing personal privacy in ubiquitous systems. Participants were divided into two groups; one group received no information about who had requested their location while the other group was able to view their location disclosure history. The four major findings of the study were that (1) providing feedback to users makes them more comfortable about sharing location (2) feedback is a desired feature and makes users more willing to share location information, (3) time and group based rules are effective for managing privacy, and (4) peers and technical savviness have a significant impact upon use.

Vihavaninen and Oulasvirta [88] performed three field trials of Jaiku, a mobile microblogging service that automates disclosure and diffusion of location information. The focus of the field trials was on investigating the use, user response and user understanding of automation. The results of this study revealed that automation caused issues related to control, understanding, emergent practices and privacy. This study is significant as it is one of the first studies to investigate the implication of automated location disclosure upon user perceptions. The study however does not investigate the implications of the use of automated LBSN upon social relationships.

An ethnographic study by Page and Kobsa explored people's attitudes towards and adoption of Google Latitude, a real-time and automated LBSN. The focus of this study was upon "how participants perceive[d] Latitude to be conceptually situated within the ecology of social networking and communication technologies" [65], based upon technology adoption, social norms, audience management, information filtering and benefits. This study while innovative, presented preliminary results based upon 12 interviews of users and non-users of Latitude.

The user studies conducted upon LBSN have matured over time, with more recent studies employing sophisticated LBSN which provide automated real-time location disclosure. These studies provide insight into user perceptions and use of LBSN however issues of control, security or trust have been neglected, although they are becoming increasingly pertinent to both location based services and online social networking technologies. Furthermore there has been no more than a cursory investigation into the implications of using LBSN upon social relationships.

\section{Towards a Study Investigating the Social Implications of LBSN on Relationships}

Location based social networking is an emerging and evolving technology with current applications still very much in their infancy. Previous works reflect the state of the technology in late 2008, utilizing hypothetical 
scenario methods or unsophisticated non-real time incarnations of LSBN. While new research has begun to utilize more sophisticated mobile software applications such as Google Latitude, a sober full-length study is absent from the literature. The need for such a study however is escalating as more and more LBSN applications proliferate, with more and more mobile Internet users being aware of the existence of LBSN and/or adopting the technology. What remains to be explored in the area of LBSN are the concepts of control, security and trust, and the effect of these emerging technologies upon social relationships.

In the months between February and May 2010, the number of fully-fledged LBSN applications more than doubled from fifty to over one hundred [89]. This is a substantial increase when one considers that in late 2009 there were about 30 functional LBSN applications, but only about 8 that people would generally say were usable, reliable, or worth using. Today, innovative developers are simply piggybacking on top of the Google platform and offering niche LBSN applications targeted at dating services, adventure sports, hobbyists, expertise and qualifications, and other demographic profiling categories. Table 2 shows a list of over 100 LBSN applications. Although this is not an exhaustive list, one can only imagine the potential for such services, and the unforeseen consequences (positive and negative) that may ensue from their widespread adoption.

Table 2. A List of LBSN Applications [89]

Aka-Aki, Belysio, Bliin, Blumapia, Blummi, Brightkite, Buddy Beacon, Buddycloud, BuddyMob, BuddyWay, buzzd, Carticipate, Centrl, CitySense, ComeTogethr, Dodgeball, Dopplr, Duzine, EagleTweet, FindbyClick, FindMe, Flaik, Footprint History, FourSquare, Foyaje, Fraced, Friend Mapper, Friends on Fire, GeoMe, GeoSpot, GeoUpdater, Glympse, Google Latitude, Gowalla, gpsME, Grindr, Groovr, GyPSii, ICloseby, iPling, Ipoki, IRL, Jentro, Junaio, LightPole, Limbo, Locaccino, Locatik, Locatrix, Locr, Locle, Loki, Loopt, MapMe, Map My Tracks, Match2Blue, MeetMoi, Meet Now Live, Microsoft Vine, Mizoon, Mobilaris, MobiLuck, Mologogo, Moximiti, My Adventures, MyGeoDiary, MyGeolog, Myrimis, myWingman, NAV2US, Now Here, Nulaz, Plazes, Pocket Life, Pownce, Quiro, Qlique, Rummble, Shizzow, Skobbler, Skout, Sniff, Snikkr, Socialight, Sparrow, Spot Adventures, SpotJots, Stalqer, The Grid, Toai, Tooio, TownKing TownQueen, Trackut, Trapster, Tripit, Troovy, Twibble, Twinkle, Twittelator, Unype, weNear, WHERE $^{\mathrm{TM}}$, Whereis Everyone, WhereYouGonnaBe, Whrrl, Zhiing, Zintin

\subsection{Trust and Technology}

Many studies concerning trust and technology focus upon trust in technology. Trust is an important aspect of human interaction, including human interaction with technology, however that interaction is a two way event, and only minimal research has been undertaken to observe the impact of technology upon trust. Two studies have been found which focus upon the effect of technology upon trust.

Vasalou, Hopfensiz and Pitt [90] examined how trust can break down in online interactions. The ways trust can break down can occur from intentional acts but also from unintentional acts or exceptional acts. The paper titled: "In praise of forgiveness: ways for repairing trust breakdowns in one-off online interactions" also proposes methods for fairly assessing the kind of offender to determine whether the offender committed an intentional act that resulted in the trust breakdown or whether the act was unintentional or exceptional.

The second study that looked at the effect of technology on trust was conducted by Piccoli and Ives [17], and explored trust and the unintended effects of behavior control in virtual teams. This study was based upon observations of the conduct of virtual teams. The findings showed that behavior control mechanisms increase vigilance and make instances when individuals perceive team members to have failed to uphold their obligations salient [17].

\subsection{Social Theory}

Social informatics studies incorporate a social theory into the study of the technology. This research will incorporate the theory of trust and its importance within friendships.

8.2.1. Trust. Trust is defined as the willingness for an individual to be vulnerable where there is the presence of risk and dependence or reliance between the parities [91]. There are two important things to note about this definition of trust. First that trust is not a behavior or choice but a state of mind where the individual is willing to make themselves vulnerable. Second, that trust is not a control mechanism but a substitute for control [92], although the relationship between trust and control is more complex than this [93]. In order to understand trust more fully it is important to understand the bases upon which trust is formed and the dynamic nature of trust.

Trust is formed upon three bases (1) cognitive, (2) emotional or relational and (3) behavioral [94]. The cognitive basis of trust refers to the "evidence of trustworthiness" or "good reason" to trust. It is not that evidence or knowledge amounts to trust but that "when social actors no longer need or want any further 
evidence or rational reasons for their confidence in the objects' of trust" and are then able to make the cognitive "leap" into trust [94]. The emotional basis of trust refers to the emotional bond between parties which provides the interpersonal platform for trust. Finally, behavioral trust is the behavioral enactment of trust. To illustrate behavioral trust consider two individuals $\mathrm{A}$ and $\mathrm{B}$ and $\mathrm{A}$ trusts $B$ with task $X$. If $B$ performs task $X$ then the trust that $\mathrm{A}$ has in $\mathrm{B}$ will be confirmed, therefore there is the behavioral enactment of trust. In the same way acting incongruently can reduce the trust. The behavioral basis of trust feeds also into the fact that trust is a dynamic concept: "[w]hen a trustor takes a risk in a trustee that leads to a positive outcome, the trustor's perceptions of the trustee are enhanced. Likewise, perceptions of the trustee will decline when trust leads to unfavorable conclusions" [92].

8.2.2. Trust and Friendship. Trust is a vitally important element of friendship. Trust secures the "stability of social relationships" [4]. Friendships are described as being "based on trust, reciprocity and equality... which is an important source of solidarity and self-esteem" [4]. And trust is described as a timelessly essential factor of friendships: "the importance of mutual commitment, loyalty and trust between friends will increase and may become an essential element of modern friendship regardless of other changes, which may be expected as the nature of social communication and contracts is transformed" [4].

\section{Conclusion}

Online social networking technologies have already transformed the way in which people interact in the virtual space. Generally, younger people are more inclined to interact via features on online social networks than with traditional forms of online communications such as electronic mail. The ability to look up a "friends" location using a location based social network, now grants individuals even greater freedom to interact with one another in an almost omniscient manner. Not only do we now know the 'who' (identity) of a person, but we also know the 'whereabouts' (location) of a person, and from the profile data available on the online social network we also know something more about one's 'context.' If used appropriately these new applications have the potential to strengthen individual relationships and provide an unforeseen level of convenience between "friends", including partners, siblings, parent-child, employer-employee relationships. However, there is also the danger that these technologies can be misused and threaten fundamental threads that society is built upon, such as trust. This literature review has attempted to establish what previous research has already been conducted in the area of LBSN, and what has yet to be done. Our future work will focus on participant realtime automated LBSN fieldwork, with a view to understanding the impact of LBSN on trust between people, and the broader social implications of this emerging technology upon society.

\section{Acknowledgements}

The authors would like to acknowledge the funding support of the Australian Research Council (Discovery grant DP0881191): "Toward the Regulation of the Location-Based Services Industry: Influencing Australian Government Telecommunications Policy”.

\section{References}

[1] R. Kling, "What is social informatics and why does it matter?," The Information Society, vol. 23, pp. 205220, 2007.

[2] K. Robert and K. Sara, "Internet paradox revisited," Journal of Social Issues, vol. 58, pp. 49-74, 2002.

[3] A. Drummond. (14 May 2010) Teenager missing after Facebook meeting, [Online]. Available: http://news.smh.com.au/breaking-news-

national/teenager-missing-after-facebook-meeting20100514-v30u.html

[4] B. Misztal, Trust in Modern Societies - The Serach for the bases of Social Order. Cambridge: Blackwell Publishers, 1998.

[5] Google. (4 February 2009) See where your friends are with Google Latitude, [Online]. Available: http:/googleblog.blogspot.com/2009/02/see-whereyour-friends-are-with-google.html

[6] R. Kling and H. Rosenbaum, "Social informatics in information science: An introduction," Journal of the American Society for Information Science, vol. 49, pp. 1047-1052, 1998.

[7] R. Kling, "Social Informatics," in Encyclopedia of Library and Information Science, 2003, pp. 2656-2661.

[8] R. Kling, "Learning About Information Technologies and Social Change: The Contribution of Social Informatics," The Information Society, vol. 16, pp. 217-232, 2000.

[9] R. Kling, "Social Informatics: A New Perspective on Social Research about Information and Communication Technologies," Prometheus, vol. 18, pp. 245-264, 2000. 
[10] D. Mackenzie, "Introductory Essay: The Social Shaping of Technology," in The Social Shaping of Technology, D. Mackenzie, Ed. Philadelphia, Open University Press: Open University Press, 1999, pp. 2-27.

[11] S. Russell and R. Williams, "Social Shaping of Technology: Frameworks, Findings and Implications for Policy With Glossary of Social Shaping Concepts," in Shaping Technology, Guiding Policy: Concepts, Spaces and Tools, K. Sorensen and R. Williams, Eds. Chetenham: Elgar, 2002, pp. 37-131.

[12] R. Williams and D. Edge, "The Social Shaping of Technology," Research Policy, vol. 25, pp. 856-899, 1996.

[13] S. Sawyer and K. Eschenfelder, "Social informatics: Perspectives, examples, and trends," Annual Review of Information Science and Technology, vol. 36, pp. 427465, 2002.

[14] R. Kling and L. Covi, "Electronic journals and legitimate media in the systems of scholarly communication," The Information Society, vol. 11, pp. 261-271, 1995

[15] W. Orlikowski, "Learning from notes: Organizational issues in GroupWare implementation," The Information Society, vol. 9, pp. 237-250, 1993.

[16] B. Kahin and J. Keller, Public Access to the Internet. Cambridge: MIT Press, 1995.

[17] G. Piccoli and B. Ives, "Trust and the Unintended Effects of Behavior Control in Virtual Teams," MIS Quarterly, vol. 27, pp. 365-395, 2003.

[18] S. Sawyer and A. Tapia, "From Findings to Theories: Institutionalizing Social Informatics," The Information Society, vol. 23, pp. 263-275, 2007.

[19] O. K. Ngwenyama and A. S. Lee, "Communication Richness in Electronic Mail: Critical Social Theory and the Contextuality of Meaning," MIS Quarterly, vol. 21, pp. 145-167, 1997.

[20] S. Hansen and N. Berente, "Wikipedia, Critical Social Theory, and the Possibility of Rational Discourse," The Information Society, vol. 25, pp. 38-59, 2009.

[21] D. Cecez-Kecmanovic, "Doing critical IS research: the question of methodology," in Qualitative Research in Information Systems: Issues and Trends. Hershey: Idea Group Publishing, 2001, pp. 141-163.
[22] D. M. Boyd, "Friendster and publicly articulated social networking," presented at CHI '04 on Human Factors in Computing Systems, Vienna, Australia, 2004.

[23] S. Counts and K. E. Fisher, "Mobile Social Networking: An Information Grounds Perspective," presented at Proceedings of the 41st Annual Hawaii International Conference on System Sciences, Hawaii, 2008.

[24] A. C. Weaver and B. B. Morrison, "Social Networking," Computer, vol. 41, pp. 97-100, 2008.

[25] C. Lampe, N. Ellison, and C. Steinfield, "A face(book) in the crowd: social Searching vs. social browsing," presented at Proceedings of the 2006 20th Anniversary Conference on Computer Supported Cooperative Work, Alberta, Canada, 2006.

[26] C. Lampe, N. B. Ellison, and C. Steinfield, "Changes in use and perception of facebook," presented at Proceedings of the ACM 2008 conference on Computer supported cooperative work, San Diego, CA, 2008.

[27] A. N. Joinson, presented at Proceeding of the twenty-sixth annual SIGCHI conference on Human factors in computing systems, Florence, Italy, 2008.

[28] J. T. Hancock and C. L. Toma, "I know something you don't: the use of asymmetric personal information for interpersonal advantage," presented at Proceedings of the ACM 2008 conference on Computer supported cooperative work, San Diego, CA, 2008.

[29] Y.-Y. Ahn and S. Han, presented at Proceedings of the 16th international conference on World Wide Web, Alberta, Canada, 2007.

[30] C. N. Chapman and M. Lahav, "International ethnographic observation of social networking sites," presented at $\mathrm{CHI}$ '08 extended abstracts on Human factors in computing systems, Florence, Italy, 2008.

[31] R. Arjan, U. Pfeil, and P. Zaphiris, "Age differences in online social networking," presented at Conference on Human Factors in Computing Systems, Florence, Italy, 2008.

[32] J. Schrammel, C. Köffel, and Tscheligi, "How much do you tell?: information disclosure behavior indifferent types of online communities," presented at Proceedings of the fourth international conference on Communities and technologies, University Park, PA, 2009. 
[33] J. DiMicco and D. R. Millen, "Motivations for social networking at work," presented at Proceedings of the ACM 2008 conference on Computer supported cooperative work, San Diego, CA, 2008.

[34] M. M. Skeels and J. Grudin, "When social networks cross boundaries: a case study of workplace use of facebook and linkedin," presented at Proceedings of the ACM 2009 international conference on Supporting group work, Sanibel Island, Florida, 2009.

[35] I. Liccardi and A. Ounnas, "The role of social networks in students' learning experiences," presented at Working group reports on ITiCSE on Innovation and technology in computer science education, Dundee, Scotland, 2007.

[36] S. Bystein and J. Rose, "The Role of Social Networking Services in eParticipation," presented at Proceedings of the 1st International Conference on Electronic Participation, Linz, Austria, 2009.

[37] R. M. Beth and M. C. John, "wConnect: a facebook-based developmental learning community to support women in information technology," presented at Proceedings of the fourth international conference on Communities and technologies, University Park, PA, 2009.

[38] J. Donath and D. Boyd, "Public displays of connection," BT Technology Journal, vol. 22, pp. 71-82, 2004.

[39] D. Boyd, "Reflections on Friendster, Trust and Intimacy," presented at Ubiquitous Computing, Workshop application for the Intimate Ubiquitous Computing Workshop, Seattle, WA, 2003.

[40] C. Dwyer, "Digital Relationships in the "MySpace" Generation: Results From a Qualitative Study," presented at Proceedings of the 40th Annual Hawaii International Conference on System Sciences, Hawaii, 2007.

[41] H. Chun and H. Kwak, "Comparison of online social relations in volume vs interaction: a case study of cyworld," presented at Proceedings of the 8th ACM SIGCOMM conference on Internet measurement, Vouliagmeni, Greece, 2008.

[42] N. Ellison, C. Steinfield, and C. Lampe, "The Benefits of Facebook "Friends:" Social Capital and College Students Use of Online Social Network Sites," Journal of Computer-Mediated Communication, vol. 12, pp. 1143-1168, 2007.
[43] K. Subrahmanyam and P. Greenfield, "Online communication and adolescent relationships," The Future of Children, vol. 18, pp. 119-128, 2008.

[44] R. Gross and A. Acquisti, "Information Revelation and Privacy in Online Social Networks " presented at Workshop on Privacy in Electronic Society, Virginia, USA, 2005.

[45] J. Snyder and D. Carpenter, "MySpace.com - A Social Networking Site and Social Contract Theory," Information Systems Education Journal, vol. 5, pp. 3-11, 2007.

[46] C. Dwyer, S. Hiltz, and Passerini, "Trust and privacy concern within social networking sites: A comparison of Facebook and MySpace," presented at Proceedings of the Thirteenth Americas Conference on Information Systems (AMCIS), 2007.

[47] D. Rosenblum, "What Anyone Can Know: The Privacy Risks of Social Networking Sites," IEEE Security \& Privacy, vol. 5, pp. 40-49, 2007.

[48] M. Mohammad and C. O. Paul, "Privacy-enhanced sharing of personal content on the web," presented at Proceeding of the 17th international conference on World Wide Web, Beijing, China, 2008.

[49] S. Katherine and L. H. Richter, "Strategies and struggles with privacy in an online social networking community," presented at Proceedings of the 22nd British HCI Group Annual Conference on HCI 2008: People and Computers XXII: Culture, Creativity, Interaction - Volume 1., Liverpool, United Kingdom, 2008.

[50] A. Levin and M. Foster, "The Next Digital Divide: Online Social Network Privacy," Ryerson University, Ted Rogers School of Management, Privacy and Cyber Crimie Institute 2008.

[51] J. Golbeck and U. Kuter, "The Ripple Effect: Change in Trust and Its Impact Over a Social Network," in Computing with Social Trust, 2009, pp. 169-181.

[52] C. James and L. Ling, "Socialtrust: tamper-resilient trust establishment in online communities," presented at Proceedings of the 8th ACM/IEEE-CS joint conference on Digital libraries, Pittsburgh PA, 2008.

[53] S. Gambi and W. Reader, "The Development of Trust in Close Friendships Formed within Social Network Sites," presented at Proceedings of the WebSci'09: Society On-Line, Athens, Greece, 2009. 
[54] L. Bilge, T. Strufe, Balzarotti, and Kirda, "All your contacts are belong to us: automated identity theft attacks on social networks," presented at Proceedings of the 18th international conference on World wide web, Madrid, Spain, 2009.

[55] G. Kaupins and R. Minch, "Legal and ethical implications of employee location monitoring," International Journal of Technology and Human Interaction, vol. 2, pp. 16-20, 2006.

[56] G. D. Smith, ""Private eyes are watching you: with the implementation of the E-911 mandate, who will watch every move you make? (Telecommunications Act of 1996: Ten Years Later Symposium)," Federal Communications Law Journal, vol. 58, pp. 705-721, 2006.

[57] E. Troshynski, C. Lee, and Dourish, "Accountabilities of presence: reframing location-based systems," presented at Proceeding of the twenty-sixth annual SIGCHI conference on Human factors in computing systems, Florence, Italy, 2008.

[58] C. Strawn, "Expanding The Potential for GPS Evidence Acquisition," Small Scale Digital Device Forensics Journal, vol. 3, pp. 1-12, 2009.

[59] Y. Xiao and B. Shen, "Security and Privacy in RFID and application in telemedicine," IEEE Communications Magazine, vol. 44, pp. 64-72, 2006.

[60] A. Masters and K. Michael, "Lend me your arms: The use and implications of humancentric RFID," Electronic Commerce Research Applications, vol. 6, pp. 29-39, 2007.

[61] B. Brown and A. Taylor, "Locating Family Values: A Field Trial of the \{Whereabouts\} Clock," presented at UbiComp 2007, 2007.

[62] L.-D. Chou, N.-H. Lai, Y.-W. Chen, Y.-J. Chang, L.-F. Huang, W.-L. Chiang, H.-Y. Chiu, and J.-Y. Yang, "Management of mobile social network services for families with Developmental Delay Children," presented at 10th International Conference on e-health Networking, Applications and Services: HealthCom 2008, Singapore, 2008.

[63] D. J. Glasser and K. W. Goodman, "Chips, tags and scanners: Ethical challenges for radio frequency identification," Ethics and Information Technology, vol. 9, pp. 101-109, 2007.

[64] L. Nan and C. Guanling, "Analysis of a LocationBased Social Network," presented at International
Conference on Computational Science and Engineering, 2009.

[65] X. Page and A. Kobsa, "The Circles of Latitude: Adoption and Usage of Location Tracking in Online Social Networking," presented at International Conference on Computational Science and Engineering, 2009.

[66] M. G. Michael, S. J. Fusco, and K. Michael, "A Research Note on Ethics in the Emerging Age of überveillance," Computer Communications, vol. 31, pp. 1192-1199, 2008.

[67] L. Perusco and K. Michael, "Humancentric applications of precise location based services," presented at International Conference on eBusiness Engineering, Beijing, China, 2005.

[68] J. Weckert, "Trust and monitoring in the workplace," presented at IEEE Symposium on Technology and Society, 2000.

[69] G. Borriello, "RFID: tagging the world," Communications of the ACM, vol. 48, pp. 34-37, 2005.

[70] J. E. Dobson and P. F. Fisher, "Geoslavery," IEEE Technology and Society Magazine, vol. 22, pp. 47-52, 2003.

[71] P. Joore, "Social aspects of location-monitoring systems: the case of Guide Me and of My-SOS," Social Science Information, vol. 47, pp. 253-274, 2008.

[72] J. E. Dobson and P. F. Fisher, "The Panopticon's Changing Geography," The Geographical Review, vol. 97, pp. 307-323, 2007.

[73] E. M. Dowdell, "You are here! Mapping the boundaries of the Fourth Amendment with GPS technology," Rutgers Computer and Technology Law Journal, vol. 32, pp. 109-131, 2005.

[74] V. Lockton and R. Rosenberg, "RFID: The Next Serious Threat to Privacy," Ethics and Information Technology, vol. 7, pp. 221-231, 2005.

[75] S. L. Garfinkel and A. Juels, "RFID Privacy: An Overview of Problems and Proposed Solutions," IEEE Security and Privacy, pp. 34-43, 2005.

[76] M. Gadzheva, "Privacy concerns pertaining to location-based services," International Journal of Intercultural Information Management, vol. 1, pp. 49, 2007. 
[77] J. L. Wang and M. Loui, "Privacy and ethical issues in location-based tracking systems," presented at Proceedings of the IEEE Symposium on Technology and Society, Phoenix, Arizona, 2009.

[78] L. Barkhuus and A. Dey, "Location-Based Services for Mobile Telephony: a study of user's privacy concerns," presented at In Proceedings of the INTERACT, 9th IFIP TC13 International Conference on Human-Computer Interaction, Zurich, Switzerland, 2003.

[79] A. Aloudat, K. Michael, and R. Abbas, "LocationBased Services for Emergency Management: A MultiStakeholder Perspective," presented at The Eighth International Conference on Mobile Business (ICMB 2009), Dalian, China, 2009.

[80] S. A. Grandhi, Q. Jones, and Karam, "Sharing the big apple: a survey study of people, place and locatability," presented at CHI '05 extended abstracts on Human factors in computing systems, Portland, OR, 2005.

[81] S. J. Fusco, K. Michael, M. G. Michael, and R. Abbas, "Exploring the Social Implications of Location Based Social Networking: An inquiry into the perceived positive and negative impacts of using LBSN between friends," presented at International Conference on Mobile Business, Athens, Greece, 2010.

[82] L. Barkhuus., "Privacy in Location-Based Services, Concern vs. Coolness," presented at HCI 2004 workshop: Location System Privacy and Control, Glasgow, UK, 2004.

[83] S. Patil and J. Lai, "Who gets to know what when: configuring privacy permissions in an awareness application," presented at Proceedings of the SIGCHI conference on Human factors in computing systems, Portland, Oregon, 2005.

[84] S. Consolvo and I. E. Smith, "Location disclosure to social relations: why, when \& what people want to share," presented at Proceedings of the SIGCHI conference on Human factors in computing systems, Portland, Oregon, 2005.

[85] L. Humphreys, "Mobile Social Networks and Social Practice: A Case Study of Dodgeball," Journal of Computer-Mediated Communication, vol. 13, pp. 341360, 2008.

[86] L. Barkhuus and B. Brown, "From awareness to repartee: sharing location within social groups," presented at Proceeding of the twenty-sixth annual
SIGCHI conference on Human factors in computing systems, Florence, Italy, 2008.

[87] J. Y. Tsai and P. Kelley, "Who's viewed you?: the impact of feedback in a mobile location-sharing application," presented at Proceedings of the 27th international conference on Human factors in computing systems, Boston, MA, 2009.

[88] S. Vihavainen and A. Oulasvirta, "'I can't lie anymore!": The implications of location automation for mobile social applications," presented at 6th Annual International Mobile and Ubiquitous Systems: Networking \& Services, 2009.

[89] C. Schapsis. (2010) Location Based Social Networks Links: A list of Location Based Social Networks, [Online]. Available: http://bdnooz.com/lbsnlocation-based-social-networking-links/

[90] A. Vasalou, A. Hopfensitz, and J. Pitt, "In praise of forgiveness: Ways for repairing trust breakdowns in one-off online interactions," International Journal of Human-Computer Studies, vol. 66, pp. 466-480, 2008.

[91] D. Rousseau and S. Sitkin, "Not So Different After All : A Cross-Discipline View of Trust," Academy of Management Review, vol. 22, pp. 393-404, 1998.

[92] R. C. Mayer and J. H. Davis, "An Integrative Model of Organizational Trust," Academy of Management Review, vol. 20, pp. 709-734, 1995.

[93] K. Bijlsma-Frankema and A. C. Costa, "Understanding the Trust-Control Nexus," International Sociology, vol. 20, pp. 259-282, 2005.

[94] J. D. Lewis and A. Weigert, "Trust as a Social Reality," Social Forces, vol. 63, pp. 967-985, 1985. 